\title{
The Teaching Reform of Combination of Flipped Classroom and PAD Class in University
}

\author{
Ai LIU ${ }^{a, *}$, Yun SHI ${ }^{b}$, Qiujing HANc and Chengzhang HAN ${ }^{d}$ \\ ${ }^{1}$ Qingdao binhai University, Qingdao, 266555, China \\ aemail:8831148@qq.com, bemail:48137474@qq.com, cemail:1246869673@qq.com, demail:42075 \\ 8217@qq.com
}

Keywords: The reform of college class teaching. Flipped classroom. PAD class.

\begin{abstract}
Flipped classroom and PAD class (Presentation-Assimilation-Discussion) are getting more and more attention and application in China. But how to realize invert in class teaching and how to guide students' active learning has become a common concern for teachers. The article proposes a new reform of college class teaching, by combing flipped classroom and PAD class together and taking advantages of each other merits and avoiding the shortcomings. The new reform is about classroom teaching practice, and can achieve better teaching results.
\end{abstract}

\section{Introduction}

Now according to the current conditions of Chinese talent market, there is a necessity in reforming class teaching for Chinese universities. It requires the educational ideas and educational concepts in the new century to guide the reform and practice [1].

In recent years, flipped classroom and PAD class achieve better teaching results in the domestic medium and small institutions, class teaching reform is in full swing. On the condition of mastering a variety of teaching methods, teachers need to make appropriate changes and improvements according to teaching subjects, to avoid blindly copy in the teaching practices.

\section{The Problems in the Educational Reform}

There is no breakthrough in sight on basic course teaching reform of circuit analysis and fundamentals of analog electronics etc. The percentage of students who passed the exam is less than $50 \%$ so the result is unsatisfactory. How to improve students' learning motivation and how to let students do active learning, has become a problem.

In recent years, flipped classroom with its unique advantages, has made great progress in China. Flipped classroom has many characteristics such as increasing participation of students, increasing teamwork, providing personalized guidance, liberating teacher etc. So many teachers choose to flip the classroom and achieve better teaching effectiveness. But there is a serious problem exists in courses with high theory, which makes it difficult to invert the flipped classroom. For example, the course of fundamentals of analog electronics is boring. So some students have no interests in learning, and then teachers dare not to try flipped classroom because of less learning motivation and bad self-study ability.

Subsequently, PAD classes are presented, the key idea is to allocate half of the class time to teacher's presentation and the other half to student discussion. The presentation and discussion are separated so that students can have one week in between for self-paced and individualized assimilation [2]. The theory of PAD class proposed three core links: presentation (P), assimilation (A), Discussion (D). So the teaching method avoid the dilemma of flipped classroom about unable to flip. But some issues emerged. Assimilation section, how to motivate students to study independently. Discussion section, due to the nature of the course, the topics discussed without departing from the basic circuit problem. So discussion becomes, basically, outstanding students explain it to others, and then students lose interests. At last, discussion can't to motivate students to learn. 


\section{Using of Combination of Flipped Classroom and PAD Class}

In view of the above problems, we consider combing the of flipped classroom and PAD class together. First, use PAD class to avoid flipping. After the teacher's presentation and students' individualized assimilation, use the ARCS theory instead of discussion section. The ARCS theory is developed by the psychologist Dr. John Keller, which proposed four components: attention (A), relevance(R), concentration(C), and satisfaction(S) [3]. It can be used to stimulate students' motivation for learning.

\section{Teachers' presentation and Students' individualized Assimilation}

Teachers in the classroom teaching pay attention to the following three points. The first is compression of class time, teachers focus on to explain the key and difficult points, and leave enough time and space to students to think and communicate. The second is students' mission of listening to lectures. The mission consists of making a mind map that will show the relations of the knowledge, finishing the homework, making relevant PPT, preparing speeches, answering questions and recording knowledge points. This is the section of students' individualized assimilation. The third is the combination of theory knowledge and practice, which can be taught by project [4].

\section{Flipped Classroom}

The pilot project for reforming of the circuit analysis course is conducted [5]. The teaching method of combination of flipped classroom and PAD class in classroom teaching is used. The whole class (45 people) is divided into 9 groups, each group of 5 people. At the same time, the important content of book is divided into nine knowledge points by teacher. Then every group is responsible for one knowledge point and guiding the classmates to review and answer questions.

Five students of each group is responsible of different tasks. Team leader is responsible for the task allocation and management of the whole group. The second student needs to make a PPT, which displays the main content and examples. The third student's responsibility is to explain the PPT, so these two students coordinate with each other and present the knowledge point to all classmates. The fourth student's task is answering questions. The fifth student is spokesman for the group. After the interpretation of knowledge points, a spokesman of other groups to put forward question on behalf of the group and can only ask a question. Every group's question can not be repeated. If time permits, any other students may be able to ask questions. Finally, teacher reviews the performance of the five students and the effect of classroom lectures.

At the end of the semester all classmates elected six awards: best team, best presenter, best PPT maker, answering best, best spokesman, special performance and rank and give score of all groups. The five students' score of the same group are identical. Award-winning students and students who receive praise from teacher reviews can get extra points. Finally, each student submits summary report, which sums up individual performance and feeling in this activity, and get personal plus points or subtract points by the report. The final score of activity will make up 30 percent of overall final grade. It highlights the process of teaching.

\section{Students' feedback}

After the end of semester course, we can find out the result of reform in teaching by analyzing the questionnaires filling out by all students. It can be found that $98 \%$ of the students are willing to participate in this educational reform activity. So students have to make time for making PPT, preparing speech, answering problems etc. outside of the classroom, it is students' individualized assimilation. All students will spend a different amount of time on assimilation such as a half hour or one hour and so on. The proportion is shown in the fig. 1 below. 


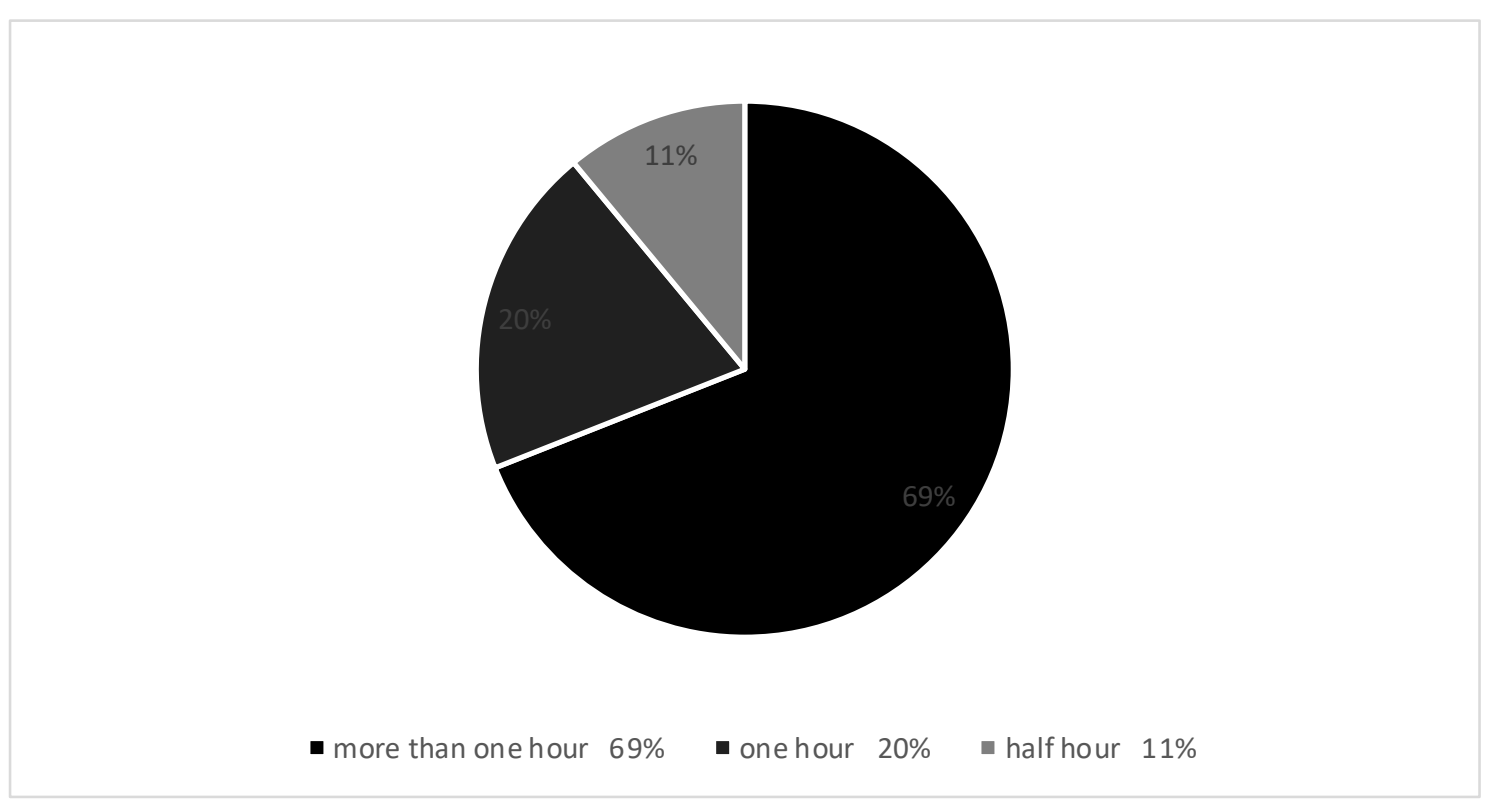

Fig.1. Spending time on assimilation

\section{Effect}

Through the teaching reform activities, the students' learning enthusiasm has been greatly aroused, and the final pass rate is greatly improved. Besides, students abilities of using brains, hands and mouth in all aspects have been improved, for example speech ability, Microsoft PowerPoint software application ability, writing word documents ability, improvising ability, using the internet to find filter materials ability, organization and coordination ability, solidarity and cooperation ability and so on. Students' evaluation of the effect about the reform is shown in the fig. 2 below.
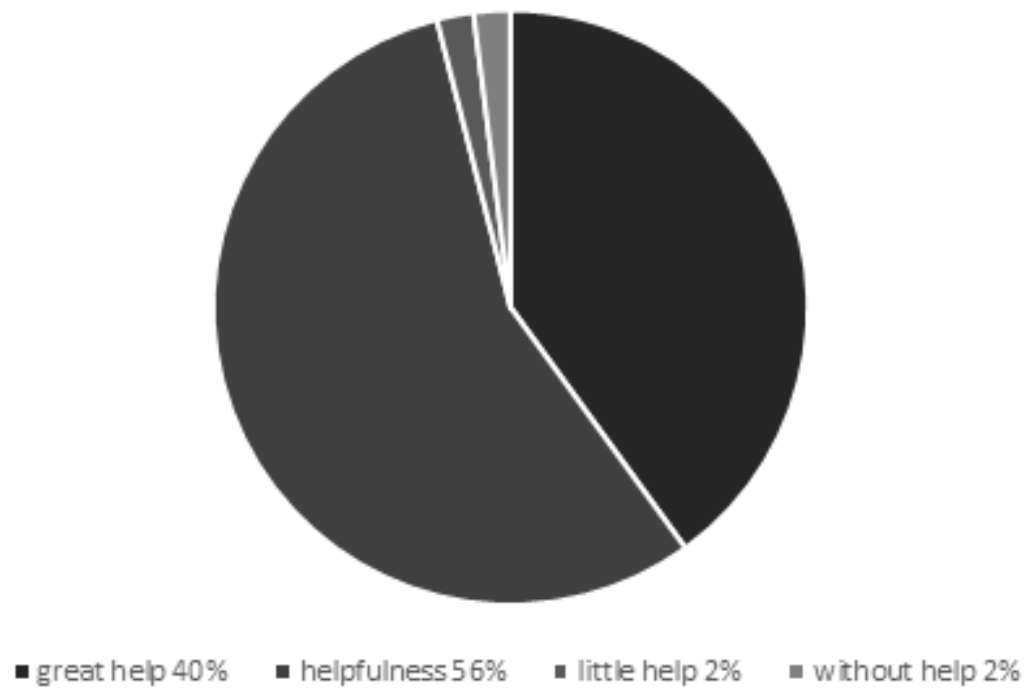

Fig.2. Student evaluation of the effect about the reform

\section{Conclusion}

The successful completion of education reform mobilizes enthusiasm of students, cultivates students' autonomous learning ability and improves comprehensive quality of students. The whole process of the educational reform is shown in Fig. 3 below. 


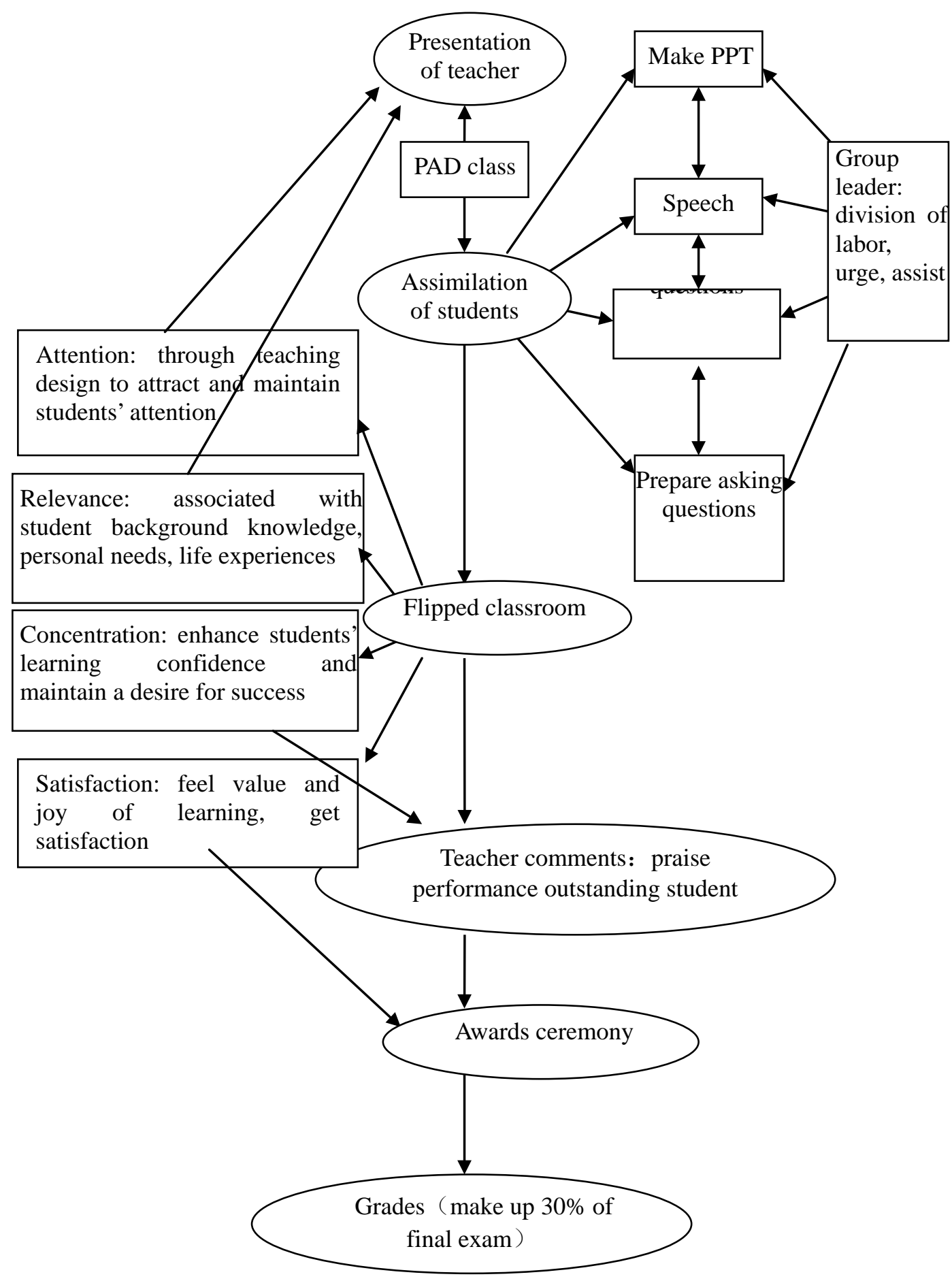

Fig.3. Sketch teaching reform process

In addition, the teaching reform is needed to deepen continually to make sure that every student can complete the task independently and avoid the situation that some students give up individualized assimilation because of various difficulties.

\section{References}

[1] Danhong MA. Problems in class teaching in Chinese universities and countermeasures in teaching reform[J]. Cross-Cultural Communication, 2015, Vol.11(11), pp.113-117.

[2] Zhang Xuexin. PAD class: a new attempt in university teaching reform[J]. Fudan Education Forum, 2014, 12(5):5-10. 
[3] Amanda Hu, Patricia A. Shewokis,Kimberly Ting, Kevin Fung. Motivation in computer-assisted instruction [J]. The Laryngoscopes, 2016, Vol.126.

[4] LIU Ai, WANG Ruixue, Discussion on the teaching reform of analog electronic technology[J]. J. Wuhan Univ. (Nat. Sci. Ed.), 2012, Vol.58.

[5] William Swart, Karl L. Wuensch. Flipping Quantitative Classes: A Triple Win [J]. Decision Sciences Journal of Innovative Education, 2016, Vol.14(1). 